\title{
Primate groups link up to oversee supplies
}

Munich. Five European primate research and breeding centres, backed by the European Commission (EC) in Brussels, have set up a common network to coordinate the supply of European-bred primates of high quality to researchers and industry, to advise on reducing the number of primates used in medicine, and to develop ethical standards for the use of primates in research.

The European Primate Resources Network (EUPREN), linking five separate centres, was established last month. One of its tasks will be to compile accurate figures of the number of primates used in Europe.

A longer term aim is to increase the supply of European primates in order to avoid importing animals. But this idea remains controversial, as some animal welfare groups claim that it detracts from a commitment to reduce the number of animals used in research.

The move comes at a time when the EC is caught between pressures to reduce the use of primates in medicine and research - particularly primates caught in the wild - and the need to maintain supplies of high quality primates where their use is unavoidable.

Europe's total primate breeding capacity - based on a relatively large breeding centre in Göttingen, Germany and smaller facilities in Strasbourg, France, and Rijswick in the Netherlands (see box) - is not much more than 500 animals per year.

But it is estimated that Europe uses 10,000 primates a year, 90 per cent by commercial companies. About one-third of this is for vaccine development and production and the rest is in drug testing and medical research.

Animals also come from breeding centres in the primates' country of origin China for example, has many such centres - or are captured from the wild. But both animal welfare groups and scientists working with primates criticize the importation of animals because of the stress caused by long-distance travel and the im- pact on wild populations.

They also agree that unregulated breeding conditions in the third world are unacceptable, while scientists often prefer not to work with animals caught in the wild, not only for ethical reasons, but also because of their unknown age and history of infection.

The EC's environment directorate, under a council of ministers' directive passed in 1986, has been instructed to move towards a complete ban on the import of animals caught in the wild and to ensure that as few as possible are used in research.

The EC's research directorate last year set up a Primate Vaccine Evaluation Network (PVEN) in an attempt to meet the implications of these moves. It operates in 69 countries, inspecting breeding centres and only admitting as members those which fulfil stringent conditions.

Michael Balls, director of the European Centre for Validation of Alternative Methods (ECVAM) at the EC's Joint Research Centre in Ispra, Italy, and an adviser to the environment directorate on the welfare of laboratory animals, says that before any move is made to increase the supply of European primate. Europe should accurately assess how many primates are really essential in medicine and research.

Balls points out that the purpose of the directive is to reduce the use of animals particularly primates - in research, and argues that it is still too easy to get approval for the use of primates.

Micha Roumiantzeff from the European Vaccines Manufacturers Association, a group representing seven companies which supply two-thirds of the world's vaccines, is concerned that attempts significantly to increase the breeding of primates in Europe could be unrealistic on economic grounds.

Vaccine production and testing, he says, as well as drug testing, are regulated by authorities that demand specific species of primate and it is difficult simply to ask

\section{Genetics institute opens in Strasbourg}

Paris. The French Institute of Genetics and Molecular Biology (right) officially opened last month at IIIkirch-Graffenstaden near

Strasbourg in France. In the first collaboration of its kind for French science, the centre was built with the support of a private company, Bristol-Myers Squibb. It has a floor area of 15,000 square metres.

The centre is directed by Pierre Chambon, whose research group was recently ranked by The Scientist as sixth in the world league of leading genetics research institutes, being credited with $\mathbf{3 0}$ per cent of French companies to cut numbers or use alternatives. He argues that, as an alternative, EUPREN should, in conjunction with PVEN, become involved in regulating the importation of animals, a suggestion currently under discussion at the commission.

Roumiantzeff says companies are also worried that the commission's plans to reduce the use of animals in research could lead to a shortage of primates for vaccine production in Europe.

Continuous supplies are needed if vaccine production is not to suffer, he says, and new breeding colonies can take years to establish. Industry still relies on import of primates caught in the wild, he says, and an immediate ban would cause problems.

Alison Abbott

\section{Reprieve for Dutch animal centre?}

Munich. A primate centre run by the $\mathrm{Na}$ tional Applied Research Organization (TNO) at Rijkswik in the Netherlands, which was threatened with closure two years ago, is likely to be saved if, as expected, the Dutch government accepts a rescue plan being submitted it next week.

A reportfrom TNO, whose conclusions are expected to be approved by the end of the year, says that the centre should be turned into an independent foundation, with its running costs shared equally by the government, the commission of the European Union, and industry.

The centre already carries out a significant amount of work for the European Commission. But in 1992, facing severe budget cuts, the TNO decided it could no longer afford to run its national primate centre, which had run up a deficit of Dfl13.7 million(US\$2 million) (see Nature 363, 4; 1993).

The decision caused an outcry from scientists in the Netherlands and elsewhere, whoemphasized the high standard of research at the centre (for example, its pioneering work on bone marrow transplantation) and the importance of its breeding colonies for AIDS research. This forced TNO to think again, and to press the government for an alternative solution.

If its rescue plan is approved, the centre - to be known as the Biomedical Primate Research Centre - will operate as an independent body. One third of its DF13.5 million annual operating costs would be guaranteed by the Dutch government for four years, with the difference made up with funds from the commission's fourth framework programme and contracts with pharmaceutical companies. A. A. 